\title{
WAVELET ANALYSIS ON EFFECTS OF CLIMATE CHANGE ON HYDROLOGY AND WATER RESOURCES
}

\author{
ZHANG, J. ${ }^{1,2}-$ FENG, M. Q. ${ }^{1^{*}}-$ WANG, Y. ${ }^{1}$ \\ ${ }^{1}$ State Key Laboratory Base of Eco-Hydraulic Engineering in Arid Area, Xi'an University of \\ Technology, Xi'an 710048, China \\ ${ }^{2}$ Shanxi Conservancy Technical College, Yuncheng 044004, China \\ *Corresponding author \\ e-mail:mqfeng@xaut.edu.cn \\ (Received $3^{\text {rd }}$ Apr 2019; accepted $17^{\text {th }}$ May 2019)
}

\begin{abstract}
The global warming has triggered climate change, which has a certain impact on the redistribution of hydrology and water resources, and may even tilts the ecological balance. This paper sums up the trends of some climate and hydrological indices in several Chinese rivers, namely, temperature, precipitation and runoff, and examines how these indices vary with the time. Then, the wavelet analysis was introduced to disclose the hidden features of temperature, precipitation and runoff time series, revealing certain correlations between these series. As a result, the effect of temperature on precipitation was explored through correlation analysis, so was that of temperature and precipitation on runoff. Finally, the ecological water demands in the upstream, midstream and downstream of the target river were computed, and found to change in a similar way to temperature and precipitation. The research findings shed new light on the maintenance of hydrology and water resources in rivers and the handling of relevant problems.
\end{abstract}

Keywords: temperature, precipitation, runoff, water resources, ecology, ecological balance

\section{Introduction}

The rapid development of global economy and industry has pushed up the emission of carbon dioxide, inducing climate warming around the world (Bertuzzo and Mari, 2017; Quilty and Adamowski, 2018). The rising temperature melts ice in polar regions, elevates the sea level and triggers various environmental problems (Liu et al., 2018; Jódar et al., 2017; Rad et al., 2017). For example, the temperature variation may cause changes in water evaporation and precipitation, exerting certain impacts on terrestrial hydrology and water resources (Ademila and Saloko, 2018; Baker, 2017; Mcknight, 2017; Moungar et al., 2018; Na et al., 2017). The redistribution of water resources in turn increases the chance of floods and droughts, tilts the ecological balance, and even endangers the survival of humans and other living things on Earth (Seiller et al., 2017; Dile et al., 2018; Zhao et al., 2017).

To solve these problems, this paper analyzes how climate conditions affect hydrology and examines the necessary hydrological conditions for ecological balance. Much research has been done on the hydrological impacts of climate conditions at home and abroad. However, there is not yet a unified understanding about how the climate affects the hydrology (Hutton et al., 2017; Blöschl, 2017; Ouyang et al., 2017). On ecology and hydrology, the study of the ecological demand for hydrology and water resources started early, yielding fruitful results. In the beginning, the water resources needed for ecology were investigated with the goal of satisfying the water demand for living organisms in river areas. Later, some scholars held that simply fulfilling this demand cannot ensure the relative stability of the ecology; the water resources should 
be sufficient to maintain a certain degree of liquidity, i.e. the ability to purify itself (Mccurley and Jawitz, 2017). Most mature ecological and hydrological models are created in developed countries in Europe and North America. European countries have developed more such models than anywhere else. Table 1 lists the applications of typical ecological and hydrological models since the 1980s.

Table 1. Typical ecological and hydrological models

\begin{tabular}{c|c|c|c}
\hline Decade & Reference & Region & Application \\
\hline $1980 \mathrm{~s}$ & Sharpley and Williams (1990) & North America & Evaluation of land and water management \\
\hline $1990 \mathrm{~s}$ & Krysanova et al. (1998) & Europe & $\begin{array}{c}\text { Hydrological simulation of vegetation } \\
\text { growth }\end{array}$ \\
\hline $2000 \mathrm{~s}$ & Ek et al. (2000) & Europe & $\begin{array}{c}\text { Development of modules containing } \\
\text { biotic and abiotic information for } \\
\text { geological information system (GIS) and } \\
\text { ecological protection/evaluation system }\end{array}$ \\
\hline $2000 \mathrm{~s}$ & Arabi et al. (2007) & North America & Hyrological prediction of water quality \\
\hline $2010 \mathrm{~s}$ & Acreman and Holden (2013) & Europe & $\begin{array}{c}\text { Evaluation of climate impact on } \\
\text { hydrology }\end{array}$ \\
\hline
\end{tabular}

As shown in Table 1, most of the existing studies consider ecological issue separately from the hydrological issue. There is no report on the relationship between the two issues. However, the relationship must be studied in order to disclose the effect of hydrological conditions on ecological balance.

To sum up, there are a series of problems to be solved, despite some research results on how climate affects hydrological conditions and how hydrology impacts ecology. Hence, this paper attempts to solve the problems concerning the relevant influence mechanisms, and shed new light on ecological protection in the context of global warming.

\section{Materials and methods}

\section{Basic information}

In this paper, Jinghe River in China is taken as the research object and denoted as river $\mathrm{A}$. The mainstream was divided into three sections: the upstream (A1), the midstream (A2) and the downstream (A3). There are three water sources of river A, namely, Laohe River (B), Nanhe River (C) and Qinhe River (D). Among them, rivers B and $\mathrm{C}$ have richer water resources than river $\mathrm{D}$. The position distribution of the hydrological station is shown in Figure 1. In Table 2, the research data were collected from six hydrological stations, which are respectively located on A1, A2, A3, B, C, D.

Table 2. The basic information on the rivers

\begin{tabular}{c|c|c}
\hline River & Watershed area $\left(\mathbf{k m}^{\mathbf{2}}\right)$ & Annual mean runoff $\left(\mathbf{1 0 0}\right.$ million $\left.\mathbf{~ m}^{\mathbf{3}}\right)$ \\
\hline A & 52,977 & 55.61 \\
B & 30,251 & 23.64 \\
C & 19,321 & 19.76 \\
D & 10,231 & 7.98 \\
\hline
\end{tabular}




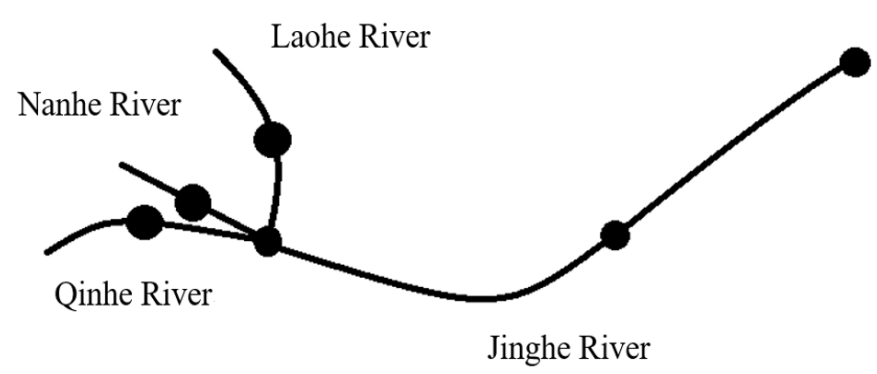

Figure 1. Hydrological station location

The statistical data in 2017 show that the watershed of Jinghe River generally enjoys abundant grassland and forestland resources. However, there are some sections with inadequate water resources, sparse vegetation and fragile ecology. The vegetation information in the upstream, midstream and downstream of Jinghe River (A1 A3) and in Laohe River, Nanhe River and Qinhe River $(\mathrm{B} \sim \mathrm{C})$ is provided in Table 3.

Table 3. The vegetation information in the watersheds of the rivers

\begin{tabular}{c|c|c|c|c}
\hline \multicolumn{2}{c|}{ Watershed } & $\begin{array}{c}\text { Forest land } \\
\text { (Million acres) }\end{array}$ & $\begin{array}{c}\text { Grassland } \\
\text { (Million acres) }\end{array}$ & $\begin{array}{c}\text { Total area } \\
\text { (Million acres) }\end{array}$ \\
\hline \multirow{3}{*}{$\mathrm{A}$ A } & A1 & 899.3 & 115 & $1,014.3$ \\
& A2 & 497.8 & 500.9 & 998.7 \\
& A3 & 100.9 & 232.9 & 332.8 \\
\hline \multicolumn{2}{c|}{ B } & $1,000.6$ & $1,098.3$ & $2,098.9$ \\
\multicolumn{2}{c|}{ C } & 438.6 & 760.1 & $1,198.7$ \\
\multicolumn{2}{c|}{ D } & 329.7 & 547.2 & 876.9 \\
\hline
\end{tabular}

\section{Climate conditions}

This paper mainly targets the meteorological data of the watershed of Jinghe River in the past 50 years (1969 2018).

\section{Temperature}

The annual mean temperature trend from 1969 to 2018 was plotted as Figure 1. The temperature trend can be linearly fitted by the Equation 1:

$$
y=0.03081 x-50.83708
$$

The coefficient of determination of the fitting formula reached 0.61097 , an evidence of good linear fitting effect. As shown in Figure 2, the temperature increased with the elapse of time, which agrees with the trend of global warming in recent decades. The rising temperature in Jinghe River watershed manifests the global warming phenomenon. Of course, Figure 2 also shows that the temperature growth was not always at the same rate in the fifty years. The rising speed was much faster in the latest 20 30 years.

The decadal temperature change in Figure 3 reflects that the temperatures in 1989 1998 and 1999 2008 were much higher than those in 1969 1978 and 1979 1988, 
and slightly higher than that in 2009 2018. In general, the temperature underwent an obvious increase, followed by a slight decline.

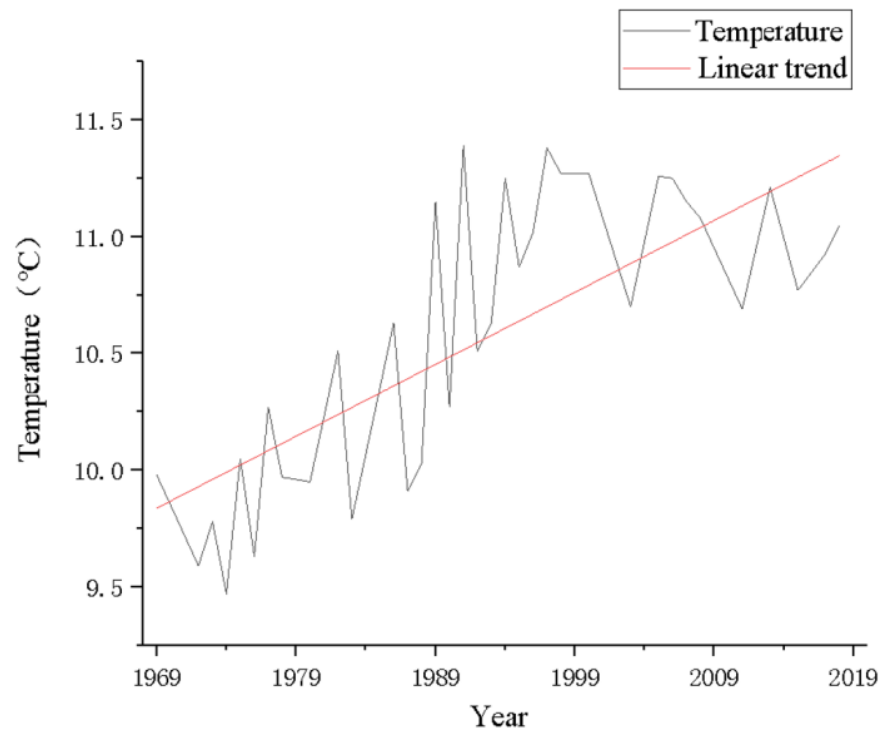

Figure 2. Interannual temperature change

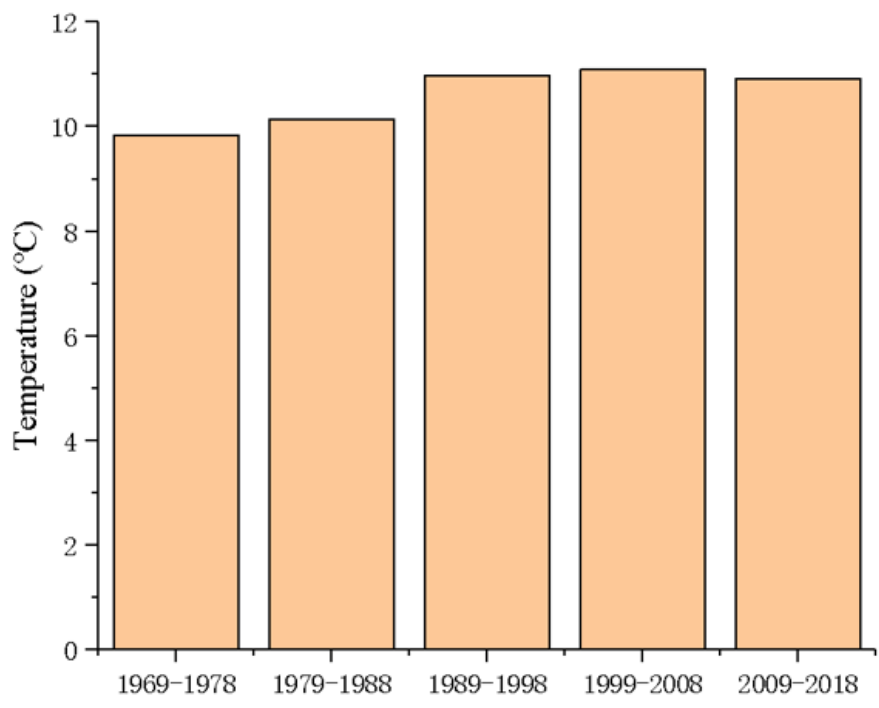

Figure 3. Decadal temperature change

\section{Precipitation}

The variation in the annual mean precipitation from 1969 to 2018 is illustrated in Figure 4. The precipitation trend can be linearly fitted by the Equation 2:

$$
y=0.94536 x-1798.87651
$$

The coefficient of determination of the fitting formula reached 0.61097, revealing a good linear fitting effect. As shown in Figure 4, the precipitation showed an obvious growth over time. 


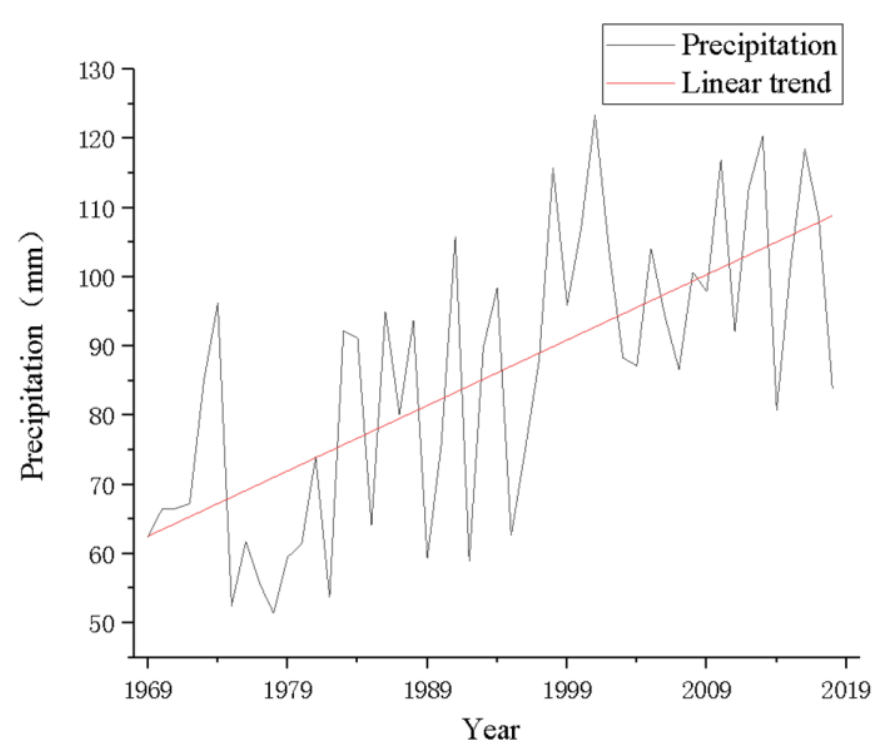

Figure 4. Interannual precipitation change

The decadal precipitation change in Figure 5 shows that the precipitation continued to rise, but at a slower speed in 2009 2018.

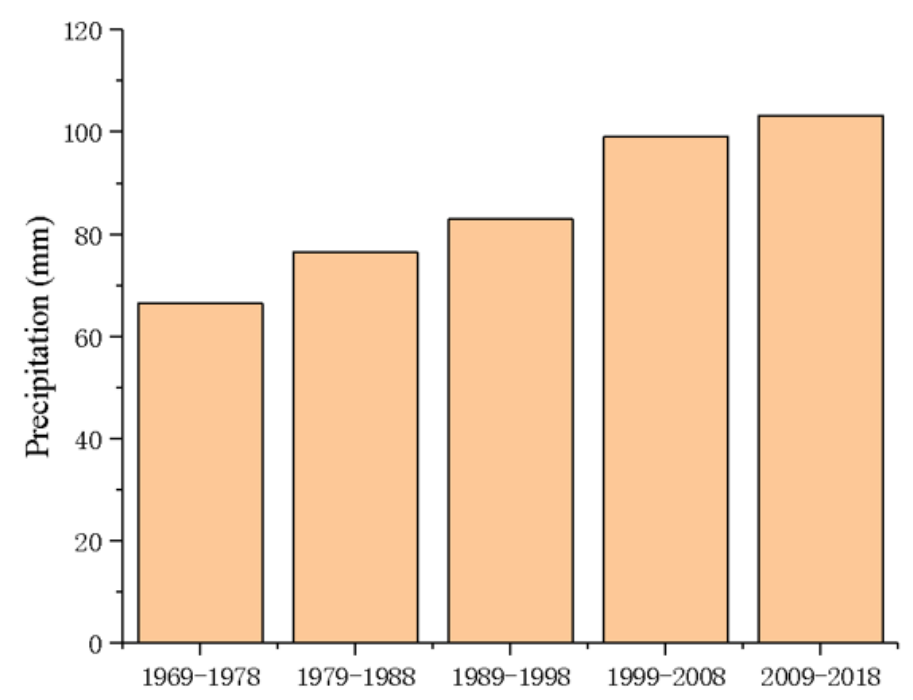

Figure 5. Decadal precipitation change

\section{Runoff features}

The redistribution of water resources is an important consequence of global warming. In this paper, the research data are collected from different hydrological stations, including the runoffs of rivers B, C and D and the three sections of Jinghe River.

The interannual runoff changes of rivers $\mathrm{B}, \mathrm{C}$ and $\mathrm{D}$ were linearly fitted by the Equations 3-5.

$$
y=0.48481 x-929.22809
$$




$$
\begin{gathered}
y=0.51626 x-979.6944 \\
y=0.32655 x-594.53929
\end{gathered}
$$

The coefficient of determinations of the above fitting formulas were respectively $0.32811,0.11164$ and 0.05515 . The slopes of Equations 3 and 4 were significantly different from 0, but the slope of Equation 5 is not. As shown in Figures 6-8, the runoffs of rivers $\mathrm{B}, \mathrm{C}$ and $\mathrm{D}$ exhibited a growing trend over time.

The interannual runoff changes of the upstream A1, midstream A2 and downstream A3 of Jinghe River were linearly fitted by the Equations $6-8$.

$$
\begin{gathered}
y=-0.3567 x+770.62988 \\
y=-0.26977 x+580.15361 \\
y=-0.42499 x+873.68232
\end{gathered}
$$

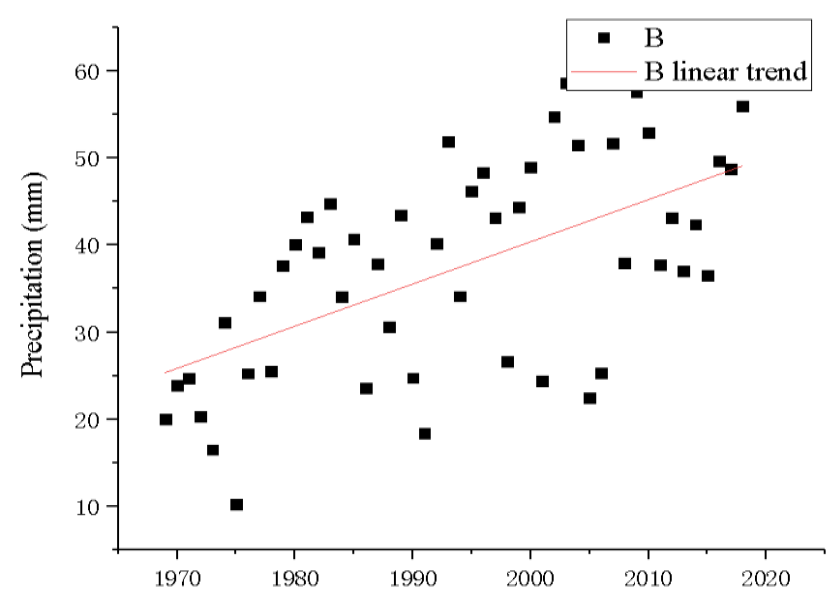

Figure 6. Interannual runoff change in River B

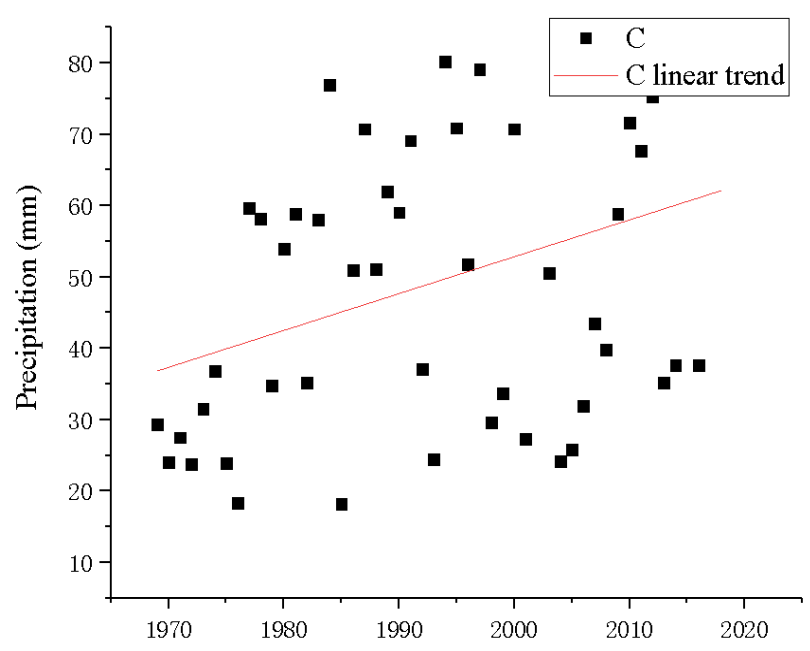

Figure 7. Interannual runoff change in River C 


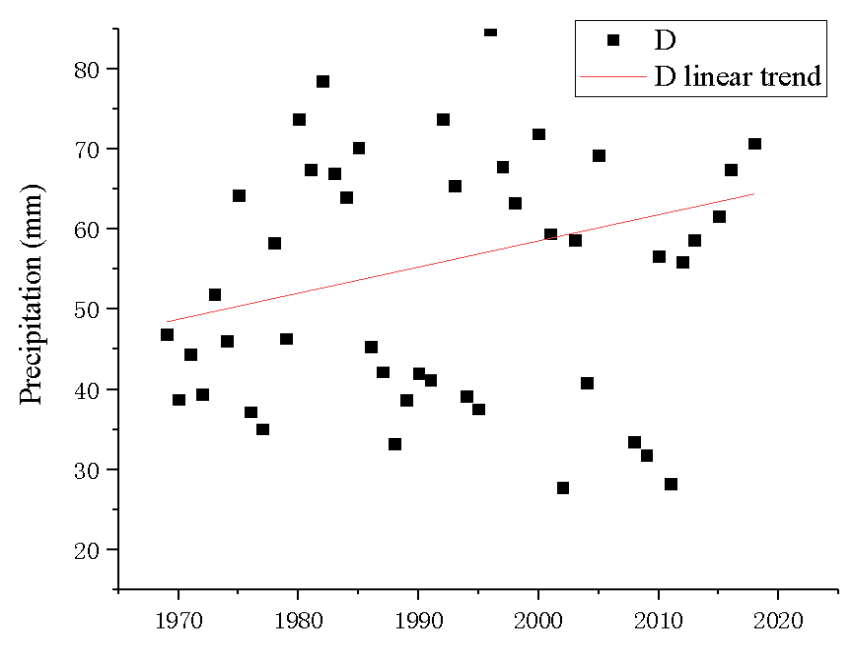

Figure 8. Interannual runoff change in River D

The coefficient of determinations of the above fitting formulas were, respectively, $0.08028,0.05$ and 0.13372 . The slopes of Equations 6 and 8 were significantly different from 0, but the slope of Equation 7 is not. As shown in Figures 9-11, the runoff of river A showed a certain decline in the research period, indicating the possible overuse of the water resources in the river. The excess water consumption for industry and agriculture may increase the water evaporation, reduce the vegetation area, and thus tilt the ecological balance.

\section{Analysis process}

Figure 12 shows our analysis process. In this paper, two important indices of climate, temperature and precipitation, are subjected to feature analysis, and then investigated to disclose how each of them affects the runoff. The index features were examined through wavelet analysis, and the runoff impacts of each index were studied by correlation analysis.

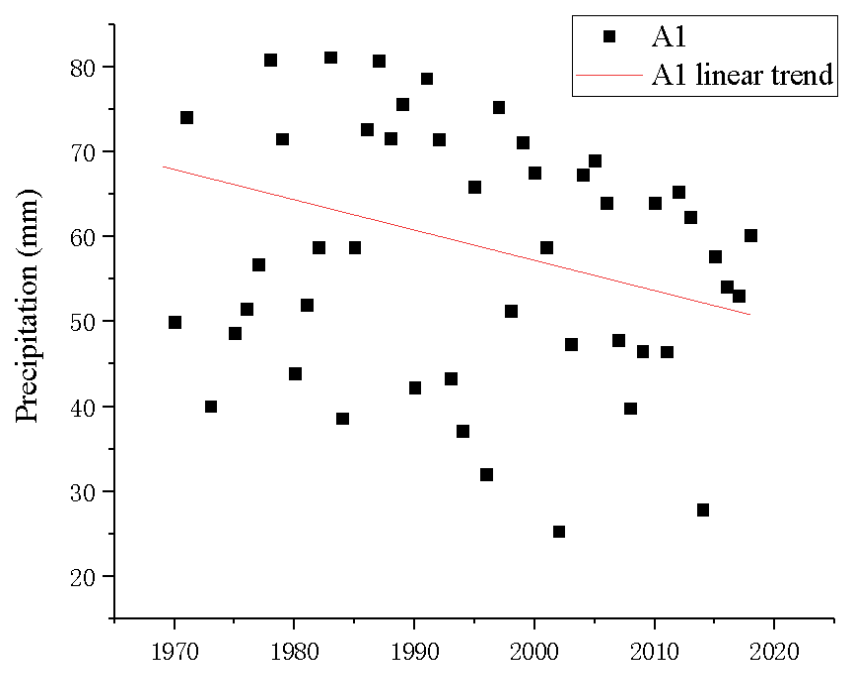

Figure 9. Interannual runoff change in Al 


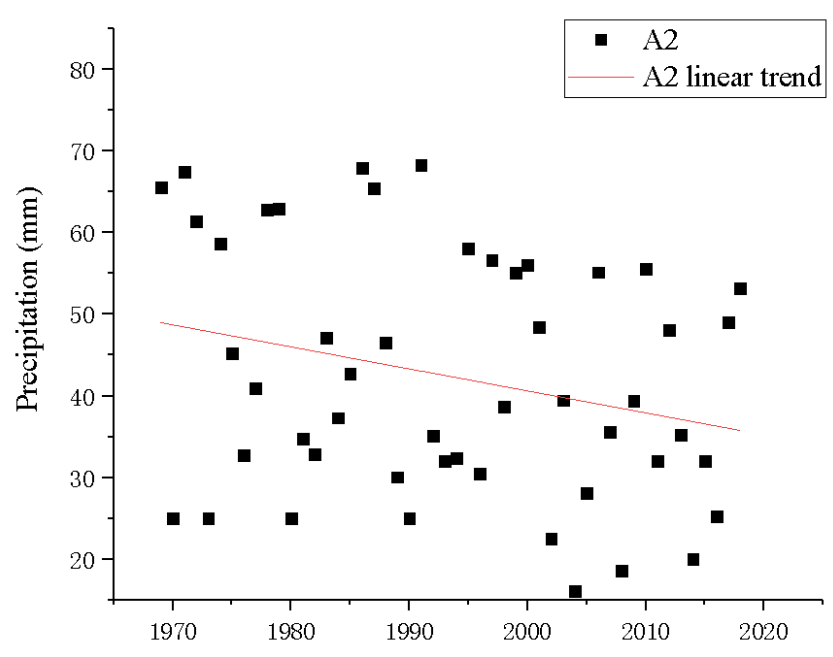

Figure 10. Interannual runoff change in $A 2$

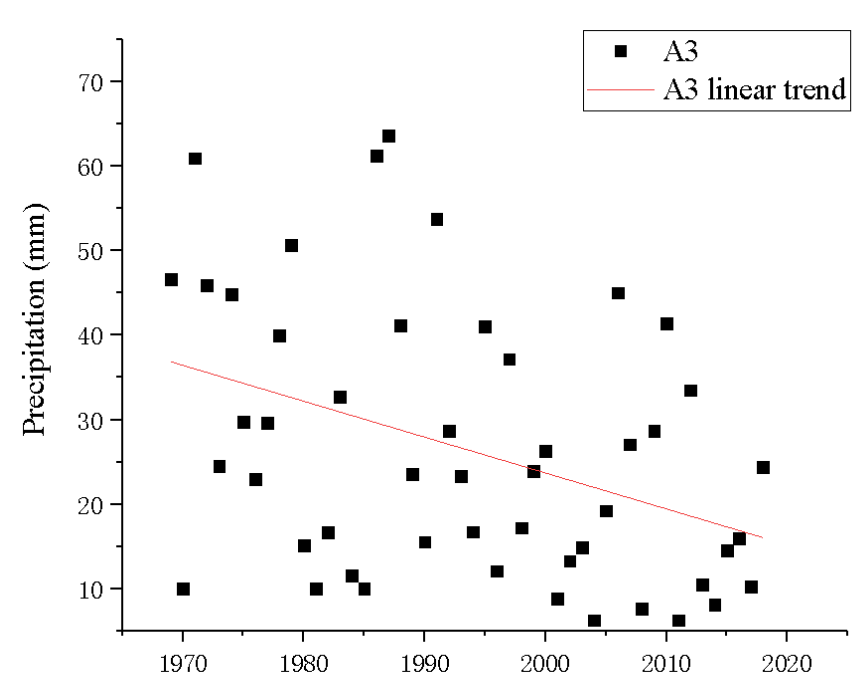

Figure 11. Interannual runoff change in $A 3$

\section{Results}

\section{Analysis of index features}

Wavelet analysis is an approach for multi-resolution statistical analysis. Compared with the traditional time series analysis, this approach does well in mining out hidden information from the research data, and enjoys great value in reference and application. In this paper, wavelet analysis is adopted to explore the data periodicity, which cannot be achieved by traditional statistical methods. The results of our wavelet analysis are listed below.

(1) The temperature time series was periodic on multiple scales, especially on the scales of 15 30, 7 22 and 2 9. The periodicity was obvious through the research period on the first two scales, and only in part of the research period on the last scale. The most obvious periodicity was observed on 15 30. 
(2) Similar to the temperature time series, the precipitation time series also exhibited periodicity on multiple scales, especially on the scales of 15 29, 6 21 and 2 7. The periodicity was obvious through the research period on the first two scales, and only in part of the research period on the last scale. The most obvious periodicity was observed on $15 \sim 29$.

(3) On the runoff time series, the runoff of Laohe River had the same strong period performance with the regional temperature, the runoff of Nanhe River had the same strong period performance with the regional precipitation, and the runoff of Qinhe River had the same strong period performance with the regional precipitation; For Jinghe River, the upstream, midstream and downstream agreed with the regional temperature in the strong period performance.

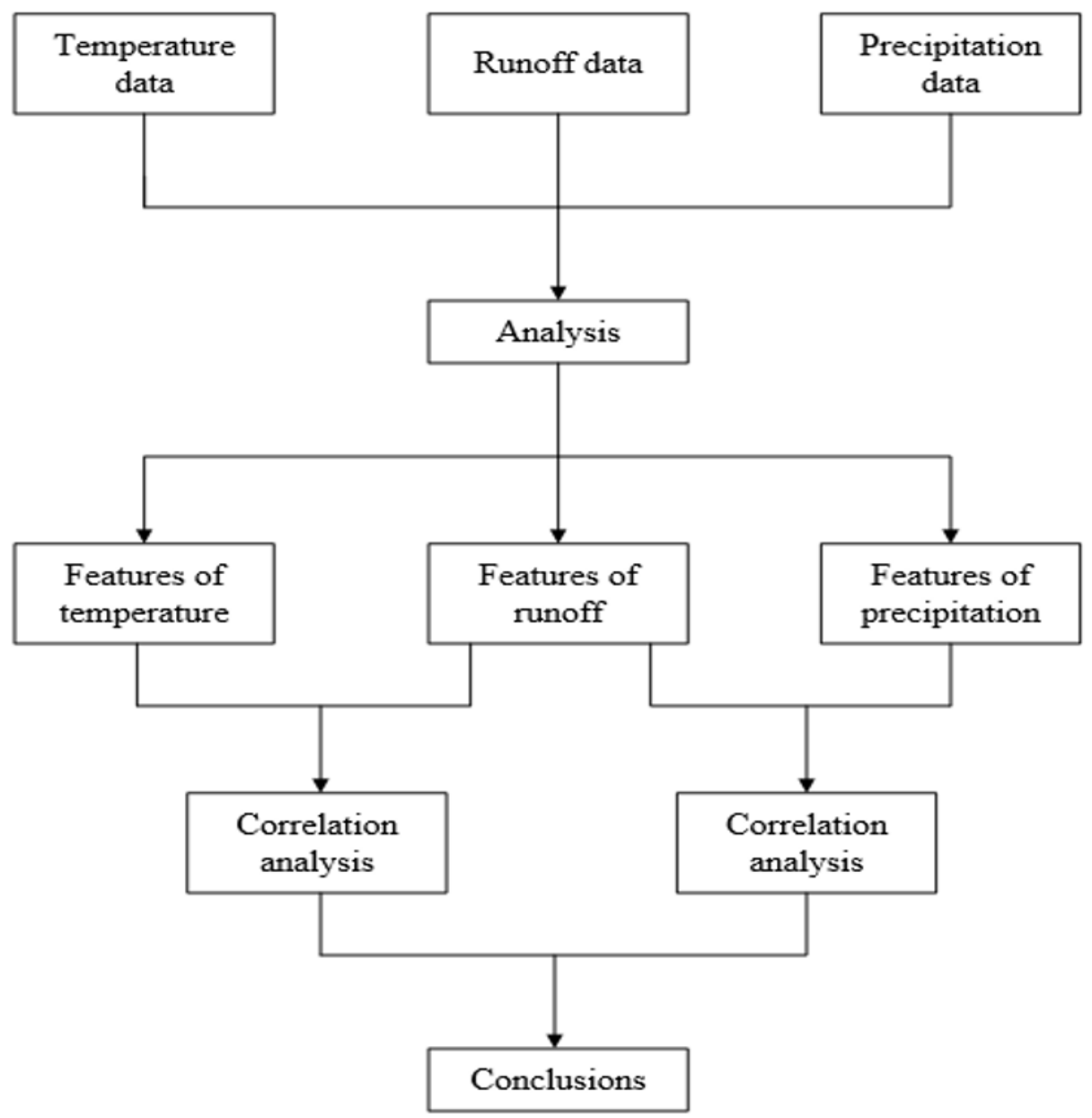

Figure 12. Analysis process

\section{Correlation analysis}

Through the analysis on index features, it is learned that the river runoffs were consistent with temperature and precipitation in strong period performance. In this subsection, the effects of temperature and precipitation are further discussed through correlation analysis. The results are shown in Table 4, where $\mathrm{T}$ is temperature, $\mathrm{P}$ is precipitation, and AR DR are the runoffs of Jinghe River, Laohe River, Nanhe River and Qinhe River (A D), respectively. 
Table 4. Results of correlation analysis

\begin{tabular}{c|c|c|c|c|c|c}
\hline & $\mathbf{T}$ & $\mathbf{P}$ & $\mathbf{A R}$ & $\mathbf{B R}$ & $\mathbf{C R}$ & $\mathbf{D R}$ \\
\hline $\mathrm{T}$ & $1 * *$ & $0.560 * *$ & $0.393 * *$ & $0.402 * *$ & $0.286 * *$ & $0.285^{* *}$ \\
$\mathrm{P}$ & $0.560 * *$ & $1 * *$ & $0.378 * *$ & $0.322^{* *}$ & $0.244 * *$ & $0.284 * *$ \\
\hline
\end{tabular}

**The corresponding statistic is significant on the level of 0.01 . The correlation analysis reveals significant correlations between temperature, precipitation and the runoffs of Jinghe River, Laohe River, Nanhe River and Qinhe River

\section{Ecological water demand}

To disclose the impacts of climate change on ecological balance, one of the keys is to check if the runoff satisfies the ecological water demand. The data on the area of different types of vegetation in Jinghe River watershed were incomplete. The only available data were recorded in 1975, 1995, 2000, 2010, 2014 and 2017. Therefore, the data on the area and density of different types of vegetation, as well as on the water demand for the normal growth of each plant, were extracted from these years, and used to compute the ecological water demands. The results are shown in Figure 13.

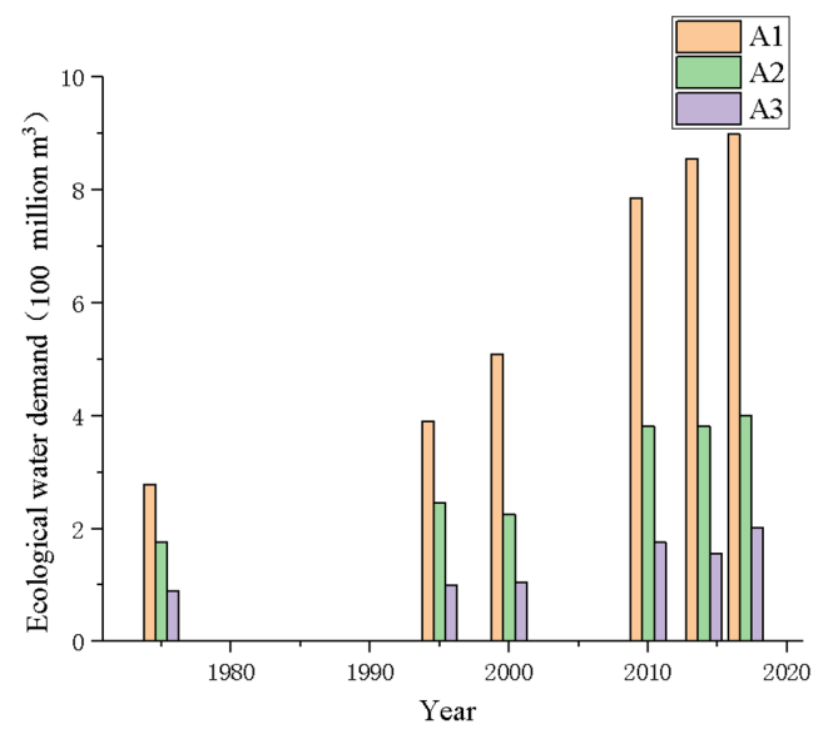

Figure 13. Ecological water demand

It can be seen from Figure 13 that the ecological water demands in the upstream, midstream and downstream of Jinghe River were all on the rise. The trend is similar to that of temperature and precipitation.

\section{Discussion}

Our research shows that both the temperature and precipitation in Jinghe River basin were on the rise in the reesarch period, which is similar to most regions across the globe (Bertuzzo and Mari, 2017). One of the more striking features of Jinghe River basin is that: the precipitation increased slightly in 2009 2018, despite the lack of obvious growth in temperature. Considering the regional vegetation area, the phenonmenon can 
be attributed to the significant growth in vegetation coverage and the further increase in evaporation in the river basis during 2009 2018.

The wavelet analysis and correlation analysis agree that temperature, precipitation and climate conditions have certain correlations with river runoff, which echoes the conclusions of the previous studies ( $\mathrm{Na}$ et al., 2017). As shown in Table 4, the temperature has a significant impact on precipitation and the two indices are positively correlated, that is, the precipitation increases with temperature. This relationship may be the result of the intense evaporation of surface water under high temperature. Meanwhile, the river runoffs are positively correlated with both temperature and precipitation, but the correlation coefficients are only 0.402 at the highest. This value is lower than that of the other studies (Bertuzzo and Mari, 2017). Hence, there must be other major water sources in the watersheds, such as glacial water and groundwater, that weakens the impact of climate indices on runoffs.

The analysis on ecological water demand indicates that the ecological water demands in the upstream, midstream and downstream of Jinghe River were all on the rise, exhibiting a similar trend to that of temperature and precipitation. This trend is consistent with the previous conclusions (Blöschl, 2017; Ouyang et al., 2017). The possible reasons are as follows. With the growth in temperature, more water is evaporated, leading to an increase in precipitation. In this situation, the vegetation area continues to expand. That is why the ecological water demand is on the rise.

Currently, the river runoff basically satisfies the ecological water demand, indicating that the ecological balance in the river shed has not been severely damaged. Of course, it should be aware that the growing vegetation coverage may reduce the amount of precipitation flowing into the river. Considering the recent runoff decline in river A (Figs. 9-11), more attention should be paid to prevent the overuse of water resources and the ensuing ecological damages.

\section{Conclusions}

(1) The trend analysis on climate indices shows that both temperature and precipitation in the research area showed an interannual growth, which echoes the trend of global warming. After analyzing the runoffs, it is noted that the upstream, midstream and downstream runoffs in Jinghe River showed a decline interannually, a signal for the possible waste of water resources in Jinghe River watershed. The waste threatens the ecological balance in the watershed.

(2) The wavelet analysis was performed to analyze the features of temperature, precipitation and runoff time series, revealing the consistency between the three indices in periodicity over time.

(3) After the correlation analysis of temperature, precipitation and runoffs, the author discovered the significant impact of temperature on precipitation, and the limited effects of temperature and precipitation on runoffs. The small correlation coefficients between runoffs and temperature/precipitation may be the result of the composition of runoff sources in the study area.

Acknowledgements. The authors would like to thank all of the researchers who participated in the project. The authors would also like to thank the Research and Extension of Water Conservancy Science and Technology in Shanxi Province (201625) for financial support. Furthermore, the authors would like to thank the anonymous reviewers for their helpful and constructive comments. 


\section{REFERENCES}

[1] Acreman, M., Holden, J. (2013): How wetlands affect floods. - Wetlands 33(5): 773-786.

[2] Ademila, O., Saloko, B. (2018): Hydrogeoelectrical evaluation of groundwater flow pattern in a Basement Complex terrain, Southwest Nigeria. - Environmental and Earth Sciences Research Journal 5(1): 7-14.

[3] Arabi, M., Rao, S. G., Hantush, M. M. (2007): A probabilistic approach for analysis of uncertainty in the evaluation of watershed management practices. - Journal of Hydrology 333(2): 459-471.

[4] Baker, V. R. (2017): Debates-hypothesis testing in hydrology: pursuing certainty versus pursuing uberty. - Water Resources Research 53(3): 1770-1778.

[5] Bertuzzo, E., Mari, L. (2017): Hydrology, water resources and the epidemiology of water-related diseases. - Advances in Water Resources 108: 329-331.

[6] Blöschl, G. (2017): Debates-hypothesis testing in hydrology: introduction. - Water Resources Research 53(3): 1767-1769.

[7] Dile, Y. T., Tekleab, S., Kaba, E. A., Gebrehiwot, S. G., Worqlul, A. W., Bayabil, H. K. (2018): Advances in water resources research in the upper Blue Nile basin and the way forward: a review. - Journal of Hydrology 560: 407-423.

[8] Ek, R. V., Witte, J. P. M., Runhaar, H., Klijn, F., Zalewski, M. (2000): Ecological effects of water management in the Netherlands: the model Demnat. - Ecological Engineering 16(1): 127-141.

[9] Hutton, C., Wagener, T., Freer, J., Han, D., Duffy, C., Arheimer, B. (2017): Reply to comment by Melsen et al. on "most computational hydrology is not reproducible, so is it really science?" - Water Resources Research 53(3): 2570-2571.

[10] Jódar, J., Carpintero, E., Martos-Rosillo, S., Ruiz-Constán, A., Marín-Lechado, C., Cabrera-Arrabal, J. A. (2017): Combination of lumped hydrological and remote-sensing models to evaluate water resources in a semi-arid high altitude ungauged watershed of Sierra Nevada (southern Spain). - Science of the Total Environment 625: 285.

[11] Krysanova, V., Müller-Wohlfeil, D. I., Becker, A. (1998): Development and test of a spatially distributed hydrological/water quality model for mesoscale watersheds. Ecological Modelling 106(2-3): 261-289.

[12] Liu, D., Guo, S., Shao, Q., Pan, L., Xiong, L., Le, W. (2018): Assessing the effects of adaptation measures on optimal water resources allocation under varied water availability conditions. - Journal of Hydrology 556: 759-774.

[13] Mccurley, K. L., Jawitz, J. W. (2017): Hyphenated hydrology: interdisciplinary evolution of water resource science. - Water Resources Research 53(4): 2972-2982.

[14] Mcknight, D. M. (2017): Debates-hypothesis testing in hydrology: a view from the field: the value of hydrologic hypotheses in designing field studies and interpreting the results to advance hydrology. - Water Resources Research 53(3): 1779-1783.

[15] Moungar, H., Azzi, A., Sahli, Y., Haida, A. (2018): Monthly fresh water yield analysis of three solar desalination units a comparative study in the south Algeria climatic condition. - International Journal of Heat and Technology 36(4): 1330-1335.

[16] Na, Y., Ke, Z., Yang, H., Zhao, Q., Qin, H., Yinshan, X. U. (2017): Evaluation of the trmm multisatellite precipitation analysis and its applicability in supporting reservoir operation and water resources management in Hanjiang basin, China. - Journal of Hydrology 549: 313-325.

[17] Ouyang, W., Gao, X., Hao, Z., Liu, H., Shi, Y., Hao, F. (2017): Farmland shift due to climate warming and impacts on temporal-spatial distributions of water resources in a middle-high latitude agricultural watershed. - Journal of Hydrology 547: 156-167.

[18] Quilty, J., Adamowski, J. (2018): Addressing the incorrect usage of wavelet-based hydrological and water resources forecasting models for real-world applications with best practices and a new forecasting framework. - Journal of Hydrology 563: 336-353. 
[19] Rad, A. M., Ghahraman, B., Khalili, D., Ghahremani, Z., Ardakani, S. A. (2017): Integrated meteorological and hydrological drought model: a management tool for proactive water resources planning of semi-arid regions. - Advances in Water Resources 107: 336-353.

[20] Seiller, G., Roy, R., Anctil, F. (2017): Influence of three common calibration metrics on the diagnosis of climate change impacts on water resources. - Journal of Hydrology 547: 280-295.

[21] Sharpley, A. N., Williams, J. R. (1990): Epic-erosion/productivity impact calculator: 2. user manual. - Technical Bulletin - United States Department of Agriculture 4(4): 206207.

[22] Zhao, C. S., Yuan, Z., Yang, S. T., Hua, X., Ying, S., Yang, Z. Y. (2018): Quantifying effects of hydrological and water quality disturbances on fish with food-web modeling. Journal of Hydrology 560: 1-10. 